Rev. Saúde públ., S. Paulo, 18(nọ esp.): 61-6, 1984.

\title{
O PAPEL DA FACULDADE DE SAÚDE PÚBLICA NA FORMAÇÃo DE RECURSOS HUMANOS PARA A SAÚDE
}

\author{
João Yunes* \\ Oswaldo Campos**
}

Ume abordagem abrangente da questao do preparo dos recursos humanos para a saú. de deve considerar seus elementos bisicos e suas inter-relaçóes em uma perspectiva histórica, e não apenas em um momento dado, para que se possa tentar apreender os seus determinantes e suas caracteristicas princi. pais. Compōem o sistema de formação de pessoal para a saúde: a populaçăo, que propicia os componentes humanos que vão alimentar o processo transformador, as ins. tituiçoes preparadoras dos ditos recursos e o produto ou resultante de tais transformaçðes que, em sua atuação sobre o ambiente, gera novas demandas condicionadoras de modificações nas entradas, processos e saídas do sistema. A sociedade, fornecedora de recursos humanos, materiais e financeiros e geradora das necessidades, que induzem demandas em saúde, forma o ambiente que determina, em última instância, os contornos mais fundamentais do dito sistema.

Pelas razóes acima, o tratamento do tema epigrafado conterá algumas considerações sobre o ambiente em que se criou a teferida Faculdade e sua atuação ao longo de sua existência. Para facilidade dividiremos a exposição em 2 partes: o período anterior ao início dos cursos da Instituição, isto é, a 1925, data da instalação do Centro de Saú. de, anexo ao Instituto de Higiene, e do primeiro Curso de Educadores Sanitários e o período posterior a estes eventos, indo até agora. Em cada um deles procuraremos discutir as demandas sociais em saúde bem como as respostas engendradas pela socieda. de $e$, no segundo, analisar o subsistema formador de recursos humanos para a saúde, conformado pela Faculdade de Saúde Públi. ca, em suas relações com os sistemas mais amplos de prestação de serviços de saúde e da sociedade paulista no período em exame, bem como os seus produtos.

\section{PRIMEIRO PERIODO - ANTERIOR A 1925}

Não há precisão no delimitar o infcio das atividades de saúde pública em São Paulo, embora o orçamento provincial de $1835 \mathrm{fi}$ zesse menção de verba consignada à vacina e em 1854 o Presidente José Antonio Saraiva tivesse nomeado uma comissão de médicos, com a incumbência de apresentar as bases para um regulamento de higiene preventiva. Em 30 de janeiro de 1884 o Dr. Marcos de Oliveira Arruda foi nomeado, em caráter interino, para o cargo de Inspetor de Higiene da Provincia de Säo Paulo, sem remuneração e nem mesmo sede ou funcionários, sendo o local de trabalho o próprio consultório desse facultativo. Em 1886, houve reforma dos serviços centrais de saúde pública, na qual era estabelecido que a Provincia de São Paulo deveria ser sede de uma Inspetoria de Higiene, composta por um Inspetor e por 2 Médicos, que foi instalada em 11 de março do mesmo ano, tendo como chefe o referido Dr. Marcos Arruda.

Após a proclamação da República foi extinta, por decreto de 14 de setembro de 1891, a Inspetoria de Higiene de São Paulo,

- Da Secretaria de Estado da Saúde - Av. Dr. Arnaldo, 351 - 01246 - Sāo Paulo, SP - Brasil. Do Departamento de Epidemiologia da Faculdade de Saúde Pública da Universidade de São Paulo. Av. Dr. Arnaldo, 715 - 01255 - São Paulo, SP - Brasil.

* Do Departamento Técnico Normativo da Secretaria de Estado da Saúde - São Paulo, SP. 
YUNES, J. \& CAMPOS, O. O papel da Faculdade de Safide Páblica na formaçắo de recursos humanos para a saúde. Rev. Saúde públ., S. Paulo, 18(no esp.):61-6, 1984.

iniciando-se, a partir de então, a estadualização dos serviços de saúde pública, tendo, em 28.10.1891, sido reorganizada a Inspetoria de Higiene que, em 18.7.92, foi definitivamente extinta, sendo, a partir de então substituída pelo Serviço Sanitário do Esta$d o^{2}$.

Pela lei $n$ ? 2018 de 26.12 .24 foi oficiali. zado o Instituto de Higiene de São Paulo, resultante da evolução do laboratório de Higiene, criado por convênio entre a Fundação Rockefeller e o Governo do Estado de São Paulo e que funcionou como cadeira da Faculdade de Medicina, tendo como primei. ro titular o Professor Samuel Taylor Darling. Tinha, O Instituto de Higiene, como finalidades realizar o curso de Higiene da Faculdade de Medicina e Cirurgia de São Paulo, bem como os cursos de aperfeiçoamento técnico para os funcionários do Serviço Sanitário, de habilitação para as enfermeiras e visitadoras de saúde pública e outros especiais que viessem a ser instituídos pela lei, ou que o Governo julgasse necessários ${ }^{2}$.

No período descrito acima, de quase 90 anos, a sociedade paulista foi sede de profundas transformaçōes que tiveram como desencadeantes a lavoura do café, a intensa imigração, a transformação das relações sociais com a abolição da escravatura, o surto de urbanização e a acelerada capitalização, decorrente de uma deliberada política de sustentação dos preços do café, que transformaram a antiga Província em um poderoso Estado de presença política marcante na República Velha ${ }^{5}$.

Ao mesmo tempo que os fatos acima ocorriam, problemas antigos, não resolvidos, na área da saúde, eclodiam com maior intensidade dados a urbanização e a incorporação de contingentes populacionais susceptiveis que, ao mesmo tempo, traziam consigo novas doenças. Assim é que a febre amarela foi reintroduzida no Brasil em 1849 pelo porto da Bahia, trazida por navio saído de Nova Orleans e que havia tocado em Havana. Da Bahia a epidemia assolou a costa brasileira, alcançou o porto de Santos e daí se interiorizou para Campinas e Ribeirão Preto, dizimando populações e ameaçando os imi- grantes que chegavam pelo porto. A esta enfermidade junte-se a vartola e a tuberculose, ambas de alta endemicidade. Em 1899 a peste também se fez presente na cidade santista. Novas doenças, entre elas o cólera, o tifo e a escarlatina foram trazidas ao pais ${ }^{5}$.

A situação acima era absolutamente disfuncional e lesira aos interesses da socieda. de que via na precária situação sanitária uma ameaça concreta à acumulação do capital. Havia, pois, que modificá-la. Como fazè-lo, porém, em uma regiáo carente de recursos humanos, dado que os médicos que praticavam seu ofício na Provincia de São Paulo eram formados alhures na Bahia, no Rio de Janeiro ou no exterior? Ademais, a maior parte dos agravos à saúde era de etiologia desconhecida e tratamento absolutamente empirico. A revolução past euriana na etiola gia das doenças e nos métodos diagnósticos bem como os avanços na química orgânica, ambos contemporâneos aos eventos que acima sumariamos, foram básicos para a primeira tentativa de equacionar e solucionar os problemas acima. Estratégicos para isso foram as sucessivas reorganizaçðes do Serviço Sanitário, sucedâneo da Inspetoria de Higiene, a criação de institutos de pesquisa e 0 início da formação de recursos humanos. As duas primeiras séries de eventos se materializaram na criação da Farmácia do Estado (1890), obrigatoriedade da vacinaçr̃o e revacinação antivariólica (1891), instalação do Instituto Vacinogènico (1892), organização do Serviço Sanitário do Estado (1892), a formação dos Institutos Serumterápico (1901) e Bacteriológico (1902). O primeiro transformou-se, posteriormente, no Instituto Butantan e o segundo, fechado e algum tempo depois reaberto, $\hat{e}$, atualmente, o Instituto Adolfo Lutz. Em 1894 surgiu o primeiro código sanitário do Estado ${ }^{2}$. A questão da formação de recursos humanos na área de saneamento pôde ser parcialmente satisfeita com a instalação da Escola Politécnica (1893). ${ }^{4}$ A existência de uma Faculdade de Medicina teve, todavia, que ser postergada até 1912 quando, em 19 de dezembro o Presidente do Estado de São Paulo sancionou a lei no 1357 , que estabeleceu o 
YUNES, J. \& CAMPOS, O. O papel de Faculdade de Saúde Pablica na formação de recursos humanos para a saúde. Rev. Saúde publ., S. Paulo, 18(no esp.):61-6, 1984.

curso da Escola de Medicina e Cirurgia de Sao Paulo que substituia a Academia de Me. dicina, Cirurgia e Farmácia, criada por lei de 24 de novembro de $1891^{4}$, porém náo instalada, pela resistência das correntes polítjcas de inspiração positivista. Só então, efetivamente, iniciou-se a formação de recursos profisionais da área médica, os quais somaram-se aos engenheiros e aos pesquisadores já existentes, entregando-se, decididamente, ao labor de controlar as epidemias que obstaculizavam o maior crescimento econômico do Estado. A solução dos mais prementes problemas pôde ser atestada pela redução da mortalidade geral que, em ascensão até 1890 , atingia a cifra de 30,73 óbitos por 1.000 habitantes, declinando para 18,14 , em $1899^{6}$. Outras questões, todavia, continuavam em pauta, entre elas as parasitoses, para cujo controle o Governo do Estado recebeu a colaboração da Fundação Rockefeller, em 1918, em intensa campanha contra a ancilostomose, com a instalação de postos nos municípios, os quais tornaram-se o embrião dos atuais Centros de Saúde. Neste mesmo ano foi criado o Laboratório de Higiene, também com a colaboração do Instituto Rockefeller, que funcionou como Cadeira da Faculdade de Medicina e que, em 1924, foi assumido pelo Governo do Estado, transformando-se em Instituto de Higiene, no qual, em 1926, foi criado o primeiro Centro de Saúde de São Paulo e o primeiro Curso de Educadores Sanitários.

- E importante destacar que os problemas de saúde mais importantes do período em análise eram as epidemias, cujo substrato eram as más condiçôes de saneamento e o contágio, entre elas predominando a febre amarela, o cólera, a peste, a variola, a tuber. culose e a malária e, em menor extensão, as doenças parasitárias. Algumas dessas doenças eram passíveis de controle por açōes sobre o meio, do tipo saneamento básico, obras de drenagem e combate a vetores. Para tanto, havia que diagnosticar corretamente e ter a disposição soros e vacinas. $O$ recurso humano era crítico quanto à sua qualidade, para conduzir as investigações clínicas e para produzir imunoterápicos. Identificado o agente etiológico da epidemia, preparado o soro para tratá-la e a vacina para preveni-la, era possível ao Estado, dada a sua riqueza material, aos engenheiros já existentes e aos pou$\cos$ médicos disponíveis, por meio de ação concentrada e pontual, reduzir a incidência da febre amarela, da peste e do cólera, por meio da eliminação do mosquito transmissor, da melhoria da qualidade da água, do sistema de esgoto e da desratização. Esse estilo de atuar caracterizou tal época como de controle das epidemias ou de policia sanitária.

Com a mudança qualitativa da nosologia, agora caracterizada pelo predomínio das doenças de massa, a situação inverteu-se. Os recursos humanos passaram a ser fundamentais, não apenas em sua qualidade, mas em quantidade e variedade, para que se pudesse interferir, favoravelmente, no processo saúde-doença, o que será discutido a seguir.

\section{SEGUNDO PERIODO - POSTERIOR A 1925}

Os três eventos relacionados, que ocorreram em 1924-25: criação do Instituto de Higiene, instalação do primeiro Centro de Saúde e realização do Curso de Educadores Sanitários, representaram propostas modernizadoras de interferência em uma realidade em rápida transformação. Esta última era constituída por uma agricultura em grande parte voltada para o mercado externo, pelo crescimento industrial e pela urbanização, com a conseqüente formação de um proletariado, numeroso e exigente de serviços permanentes de saúde e de uma classe média com padrões diferenciados de consumo de serviços, ao lado de grupos populacionais voltados para a agricultura de subsistência.

O Instituto de Higiene, com suas finalidades de realizar o curso de higiene da Faculdade de Medicina e Cirurgia de São Paulo, cursos para o aperfeiçoamento técnico para funcionários do Serviço Sanitário, de habilitação profissional para enfermeiras e visitadoras de saúde pública e outros, de promover pesquisas de caráter geral ou local, verificar os soros e vacinas expostos à venda, padro- 
YUNES, J. \& CAMPOS, O. O papel da Faculdade de Saúde Pública na formação de recursos humanos para a saúde. Rev. Saúde públ., S. Paulo, 18(n? esp.): 61-6, 1984.

nizando-os assim como orientar o ensino popular de higiene e a propaganda sanitária em geral $^{2}$ foi fundamental na "produçāo" de vários novos profissionais que passaram a compor e ampliar a equipe de saúde, desem. penhando suas funções dentro de um novo conceito de saúde pública ou de saúde coletiva, qualquer que fosse a conotação assumida pelo termo "coletivo".

A proposta de um novo modelo de atendimento à população, consubstanciada no Centro de Saúde, que chegou no bojo de uma reforma do Serviço Sanitário do Estado (decreto nQ 3876, de 11.07.25 e lei nQ 2121, de 30.12.25), representou "uma mudança completa nos rumos seguidos até então pelos serviços de saúde pública. Com ela saimos da fase de politica sanitária para entrar na de educação sanitária". . Uma das inovações foi exatamente a criação de uma Inspetoria de Educação Sanitária e Centros de Saúde incumbida de "promover a formação da consciência sanitária da população em geral e dos serviços de profilaxia geral e especifica". Os Centros de Saúde deveriam procurar atrair a população para tratá-la nos casos indicados ou encaminhá-la a instituições adequadas, padronizar os tratamentos das doenças transmissíveis, localizar focos, criar condiçoes para educar o paciente e a família. Previa-se que ali haveria cozinhas, lactários e leite que seria distribuido a preço de custo. Delimitava-se, também, uma área de atuação para cada Centro.

A inovação não passou incólume. Seus detratores acoimavam-na de mais uma "fantasia teórica" e houve dificuldades insuperáveis para difundir o modelo, que contemplava, ainda, a criação de Posto de Higiene, visitação domiciliar e a instituição do tempo integral para os trabalhadores da saúde.

A criação do Curso de Educadores Sanitários, em 30 de dezembro de 1925 constituiu-se em outra medida pioneira, tanto pelo seu ineditismo no país ${ }^{3}$, quanto pela concepção de transmitir a jovens egressas de escolas normais os conhecimentos de higiene que as habilitassem a tomarem-se agentes de transformação social e cultural, também na área de saúde.
O desenrolar do evento que é objetivo preferencial de nossa análise - a formação de recursos humanos para a saúde, conduziu ao início dos Cursos de Higiene e Saude Pública para Médicos (1929), ao reconhecimento oficial do Instituto de Higiene e Saúde Pública (1931), sua incorporação à Universidade de São Paulo (1938), aos cursos para nutricionistas (1939), a transformação em Faculdade de Higiene e Saúde Pública (1945), a instalação do Serviço Especial de Saúde de Araraquara (1947) ao começo do Curso de Saúde Pública para Engenheiros (1949), ao primeiro Curso de Administração Hospitalar do pais (1949) e a transformação em Faculdade de Saúde Priblica (1969) ${ }^{7}$.

Em sua sexagenária evolução, a instituição em tela foi se recompondo em sua tarefa de formar recursos humanos, tanto em função das formas históricas assumidas pelo "coletivo", como objeto de saber e de intervenção - o meio, objeto privilegiado das prá. ticas de saneamento ambiental, o agente patogênico e seu campo de expansão e contenção e o social, como campo estruturado de práticas, quanto pelas demandas impostas pelo ambiente ${ }^{1}$.

Graças a esta plasticidade, os produtos de sua transformação, ou seja, os egressos de seus diferentes cursos desempenharam papel fu. ¿iamental na área de saúde, ao criar novas formas de atuação que, ao superar a fase de educação sanitária da saúde pública, introduziram esquemas de ação integral, baseados no modelo de história natural da doença, ou em uma perspectiva ecológica ou mesmo estrutural funcional. Testemunhos dessa produção são, entre outros, trabalhos acadèmicos na área da ecologia médica, da demografia e sua relação com a questão social, da inovação na pesquisa epidemiológica, da nutriçăo e estrutura social, da am pliação da abordagem da epidemiologia clássica para abranger as relações entre saúde e trabalho. Também na área da prática de saúde vale destacar linhas temáticas discutindo as questões do planejamento e da reorganização administrativa como elemento de racionalização e de aumento da produtividade. As tendências acima enumeradas e outras, 
YUNES, J. \& CAMPOS, O. O papel da Faculdade de Saúde Pablica na formação de recursos humanos para a saúde. Rev. Sauide puibl., S. Paulo, 18(n? esp.): 61-6, 1984.

por um de nós recentemente analisadas ${ }^{1}$, evidenciam parte da elaboração teórica que teve como conseqüências práticas ao nível institucional as reformas que criaram a $\mathrm{Se}$ cretaria de Educação e Saúde Rública (1931), a Secretaria de Saude Pública e Assistência Social (1947) e a atual Secretaria de Estado da Saúde (1968).

Ao nível da saúde da população tais acontecimentos contribuíram positivamente para erradicar doenças de alta endemicidade, como a malária e a varíola, bem como controlar a maioria das doenças transmissíveis, além de implantar uma extensa rede de serviços de saúde que, a partir de 1970, expandiu sua cobertura em uma perspectiva de estabelecimento de um sistema de assistência primária, como porta de entrada de um conjunto hierarquizado, de complexidade crescente, que progressivamente vem incorporando à sua atuação a assistência médica.

É nesta perspectiva, ancorado ha história pretérita da Faculdade de Saúde Pública, que cabe especular sobre a sua atuação futura.

O ambiente atual, onde a instituiçăo em exame, como formadora de recursos huma. nos e produtora de conhecimentos, está inserta, é uma sociedade altamente complexa, intensamente articulada, apresentando um quadro nosológico que reflete a diferencial apropriação do produto social pelos grupos que a compðe, o que se traduz por padrőes de doenças de áreas extremamente carentes (infecto-contagiosas, violências, elevada mortalidade infantil, com a conseqüente baixa expectativa de vida), convivendo com um perfil de doença de sociedade amplamente industrializada (neoplasias, cardiovasculares, suicídios, acidentes).

Os senviços de saude existentes, subjugados à lógica da acumulação e da compet ição, ainda quando não tenham objetivo explicito de lucro, são relativamente pouco articulados, em que pese recentes tentativas nesse sentido, do tipo do Plano de Ação Conjunta, entre o Ministério da Saúde e as Secretarias Estaduais de Saúde, ou do Plano de Açōes Integradas de Saúde, entre o Ministério da Previdência e Assistência Social, as Secretarias Estaduais e as Instituiçðes $\mathrm{Mu}$ nicipais de Saúde.

No que se refere aos serviços privados, na maior parte organizados sob a forma de empresas de prestação de serviços, cujo grande cliente é o Instituto Nacional de Assistência Médica da Previdência Social (INAMPS), acentua-se uma tendència cada vez maior de procurar a expansão, tanto vertical, pela associação com o capital financeiro, por meio das companhias de seguro-saúde, quanto horizontal, pelos convênios de assistência médica com empresas industriais e comerciais.

No quadro acima esboçado, o que esperam as instituiçőes prestadoras de serviços de saúde, sejam elas públicas ou privadas, que constituem o chamado "aparelho utilizador" das entidades formadoras de recursos humanos, também referidas como "aparelho formador", das quais a Faculdade de Saúde Pública é um dos exemplos mais conspícuos.

Em primeiro lugar, que tais instituiçסes preparem profissionais capazes de entender, em toda a sua dimensão e inter-relações, o complexo fenômeno saude-doença, o que supõe, no mínimo, a superação da tradicional visão fundamentada na história natural da doença.

Em segundo lugar, que sejam elaborados conhecimentos que permitam uma correta interpretação do "coletivo ou social", como um "campo estruturado de priticas", de tal maneira a fundamentar uma ação coerente, efetiva e eficaz.

Em terceiro lugar, que sejam desenvolvidas e transmitidas tecnologias adequadas para uma efetiva intervenção na parcela da realidade que é objeto privilegiado da ação do administrador de serviços de saúde, de tal maneira a transformá-la para consecução dos objetivos substantivos do sistema de saúde, ou seja, o melhor estado de saúde da população.

$E$, finalmente que aos profissionais que por ela transitam sejam oferecidas oportunidades para adquirir as demais competências que os tornem, efetivamente, agentes sociais de mudanfa. 
YUNES, J. \& CAMPOS, O. O papel da Faculdade de Saúde Páblica na formaģão de recursos humanos para a saúde. Rev. Saúde príbl., S. Paulo, 18(no esp.):61-6, 1984.

\section{REFERENCIAS BIBLIOGRAFICAS}

1. DONNANGELO, M.C. \& CAMPOS, O. Formaça de quadros de pessoal para a saúde e produção de conhecimentos na área médica. Sáo Paulo, FUNDAP, 1981. [Mimeografado].

2. MASCARENHAS, R.S. Contribuição para o estudo da administração sanitária estadual em São Paulo. São Paulo, 1949. [Tese de Livre-Docência - Faculdade de Higiene e Saúde Pública da USP].

3. SANTOS, P.S. Cinqüentenário da Faculdade de Saúde Pública da USP. [Editorial]. Rev. Saúde públ., S. Paulo, 9: 95-7, 1975.
4. SILVA, P.D. Notas para a memória histórica da Faculdade de Medicina de Sto Paulo. Ann. Fac. Med. S. Paulo, 1:1-77, 1926.

5. SINGER, P.; CAMPOS, O. \& OLIVEIRA, E. M. Prevenir e curar: o controle social através dos serviços de saúde. São Paulo, Forense, 1978.

6. STEPAN, N. Beginings of Brazilian science. New York, Science History Publications, 1976.

7. UNIVERSIDADE DE SĀO PAULO. Faculdade de Saúde Pública. Catálogo geral São Paulo, 1982. 